\title{
Sex and violence in hermaphrodites
}

D ifferences in objectives between males and females are a driving force in the evolution of copulatory mechanisms. Hermaphrodites can also have sexual conflicts, but caused by opposing sexual interests within rather than between individuals. One consequence seems to be that physically damaging sex, as occurs with the marine flatworm Pseudoceros bifurcus, might be favoured more in hermaphrodites than in species with separate sexes.

Most animals transfer sperm in copula, a genital 'handshake' under strong female control ${ }^{1}$. However, a widespread alternative involves injecting sperm under the partner's skin. This method is well-known in hermaphrodites such as leeches ${ }^{2}$, flatworms ${ }^{3}$ and sea slugs ${ }^{4}$, but rare when sexes are separate $^{1}$. For males, injecting sperm offers direct access to eggs, whereas females bear the costs of wound healing and lose control over fertilization ${ }^{1}$. Selection on females to avoid these costs must be strong but, in a hermaphroditic population, individuals can weigh the costs of being stabbed against the benefits of stabbing others. Observations on Pseudoceros bifurcus Prudhoe, a polyclad, marine flatworm, show that individuals indeed attempt to increase sperm donation over sperm receipt.

We collected P. bifurcus at Heron Island (Queensland, Australia) at 15-20 metres depth. Seventeen pairs were assembled such that each individual could be recognized by size or coloration. We observed them in 4litre containers with seawater and coral sand. After a first session (20 hours, seven pairs) we found mating activity did not change with time, so we shortened later sessions to $6 \mathrm{~h}$ (five pairs) and $4 \mathrm{~h}$ (five pairs). Sexually interacting individuals rear up and evert their penis on contact (Fig. 1a). When both individuals rear up, escalated contests ensue, lasting for $20.3 \pm 12.6$ minutes (mean \pm s.d.) (maximum 59 min; $n=39,14$ pairs). Individuals try to stab one another, but show strong avoidance behaviour when struck by their partner. During 39 contests, 287 strikes led to 46 inseminations in 12 pairs. Cases where only one animal reared up were frequent $(n=72)$ but resulted in only four inseminations because the nonresponding individual glided out of reach.

These results suggest 'rearing up' has evolved specifically to interact with a sexually responding partner. The behaviour is effective for 'striking and parrying': the average number of inseminations per contest was similar for both partners within a pair (intraclass correlation coefficient ${ }^{6}$ $\left.r_{\mathrm{i}}=0.65, F_{(11,12)}=4.6, P=0.007\right)$, indicating that the chances of hitting or being hit were closely matched. Importantly, most insemi-
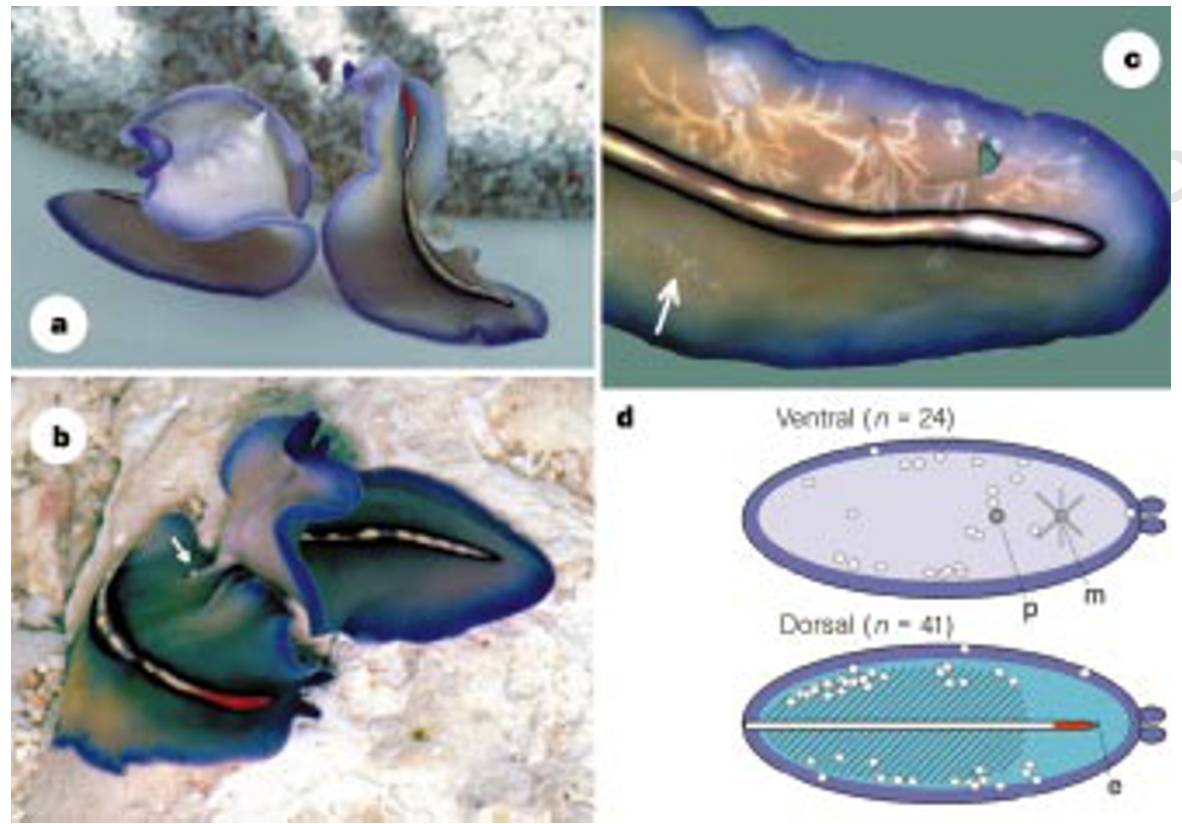

d

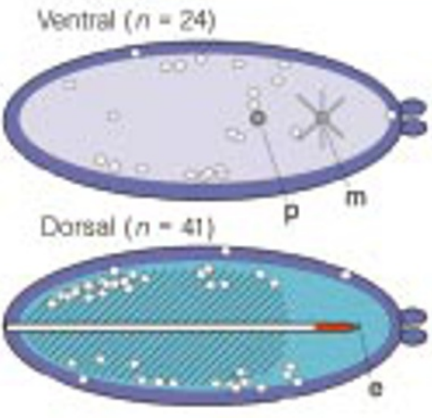

Figure 1 'Penis fencing' in $P$. bifurcus. a, Two individuals (4-6 cm long) rearing up with everted penises, attempting to inseminate their opponent while avoiding being inseminated. The left individual is turning away, having been struck unsuccessfully. $\mathbf{b}$. Unilateral insemination by one partner. Sperm is transferred for the duration of penis insertion, resulting in a sperm droplet under the partner's skin (arrow). c, Sperm moving through the body after several inseminations. The two holes in the upper half were caused by ventral and dorsal inseminations in the same place. Time since insemination: 24-36 $\mathrm{h}$ for the upper half, 3 days for the white dots (arrow). d, Summary of all injection sites (17 experimental pairs and exploratory observations). Ovaries are many and small, scattered dorsally (shaded area), making ventral injections less effective, as the widely branched gut separates ventral and dorsal halves. p, penis; m, mouth; e, light-receptor cells.

nations were unilateral $(n=30$ events; Fig. $1 b)$. Even when reciprocal penis insertion could be achieved by the second partner $(n=10$ events), the first to inseminate obtained a longer injection time than the second $(9.5 \pm 2.9$ and $5.7 \pm 4.2 \mathrm{~min}$, respectively; paired $t_{(6)}=3.04, \quad P=0.023 ; n=7$ pairs; data weighted per pair). The asymmetrical outcome of inseminations favours animals that inject first, as they will father more eggs in more partners and have fewer wounds to heal (Fig. 1c).

Although 'penis fencing' can best be explained as an attempt to increase the benefit of sperm donation over the cost of sperm receipt, the exact relation between insemination and fertilization is still unknown. Avoidance of insemination might not only cut costs but also offer the benefit of being inseminated by better 'stabbers', resulting in more successful offspring. Mate choice alone, however, seems insufficient to explain the evolution of a costly and risky behaviour in which the winner is determined primarily by chance and where sperm receipt seems to be in the wrong place in many cases (Fig. 1d). Since animals often do not meet again for hours, repeated contests between the same two partners must be rare in the wild.

The mating system of $P$. bifurcus differs from that of hermaphrodites without hypodermic insemination, where partners cannot take advantage of each other and typically exchange gametes by controlled reciprocity (ref. 7 and refs therein). Hypodermic insemination, when present, allows hermaphrodites to skew sexual interactions in favour of sperm donation, fuelling an evolutionary arms race between strike and avoidance behaviour.

\section{N. K. Michiels}

Max-Planck-Institut für Verhaltensphysiologie,

Seewiesen, Postfach 1564,

D-82305 Starnberg, Germany

e-mail:michiels@mpi-seewiesen.mpg.de

\section{J. Newman ${ }^{\star}$}

Zoology Department, University of Queensland, QLD Australia 4072

\footnotetext{
1. Eberhard, W. G. Female Control: Sexual Selection by Cryptic Female Choice (Princeton Univ. Press, Princeton, 1996).

2. Malecha, J. in Reproductive Biology of Invertebrates $\mathbf{5}$ (Sexual Differentiation and Behaviour) (ed. Adiyodi, K. G. \& Adiyodi, R. G.) 231-248 (John Wiley, Chichester, 1992).

. Apelt, G. Mar. Biol. 4, 267-325 (1969).

4. Tompa, A. S., Verdonk, N. H. \& van den Biggelaar, J. A. M. The Mollusca 7 (Reproduction) (Academic, Orlando, 1984).

. Newman, L. J. \& Cannon, L. R. G. Mem. Queensl. Mus. 37(1), 205-266 (1994)

6. Sokal, R. R. \& Rohlf, F. J. in Biometry 213-214 (Freeman, New York, 1995).

Petersen, C. W. Envir. Biol. Fishes 43, 351-361 (1995).

* Present address: National Museum of Natural History, Smithsonian Institution, Washington, DC 20560, USA.
} 